\title{
Freqüência de anticorpos anti-Neospora caninum e anti-Toxoplasma gondii em soros de bovinos pertencentes aos estados de São Paulo e de Minas Gerais
}

\author{
Frequence of antibodies for Neospora caninum and Toxoplasma gondii in cattle, \\ São Paulo and Minas Gerais States
}

\author{
Gustavo Henrique Nogueira Costa ${ }^{1,2}$; Dagmar Diniz Cabral ${ }^{3}$; Nancy Prette Varandas ${ }^{1,2}$; \\ Elizângela de Almeida Sobral ${ }^{1}$; Fernando de Almeida Borges ${ }^{1,2}$; Karina Carrão Castagnolli1,2
}

\begin{abstract}
Resumo: Foram colhidas 600 amostras de soros de vacas, pertencentes a propriedades rurais dos municípios de Pirangi, Votuporanga, Guaíra e Ituverava, Estado de São Paulo e dos municípios de Iturama e Gurinhatã, Estado de Minas Gerais. As amostras foram analisadas pela técnica de imunofluorescência indireta (RIFI-lgG), para a pesquisa de anticorpos contra Neospora caninum e contra Toxoplasma gondii. Os exames sorológicos revelaram 16,83\% e $49,17 \%$ de animais sororreagentes ao N. caninum e ao T. gondii, respectivamente. Foram encontrados 54 (9,00\%) animais apresentando títulos de anticorpos para ambos coccídios. Em todos os municípios analisados foi detectada a presença de animais sororreagentes. Diferenças estatísticas $(P<0,05)$ foram constatadas nos resultados da sorologia entre alguns municípios, utilizando-se o método de Qui-Quadrado $\left(X^{2}\right)$. Pode-se inferir, portanto, que infecções por $N$. caninum e $T$. gondii estão disseminadas em bovinos provenientes de rebanhos dos municípios avaliados e que a frequência simultânea de anticorpos $(9,00 \%)$ contra os dois coccídios ( $N$. caninum e $T$. gondii) pode ser considerada relativamente alta.
\end{abstract}

Palavras-chave: Neospora caninum, Toxoplasma gondii, freqüência, bovinos.

Abstract: 600 samples of bovine sera, taken from cows from four counties in the São Paulo State and from two counties in the Minas Gerais State, Brazil, were tested using an immunofluorescent antibody technique (RIFI-IgG) for the presence of Neospora caninum and Toxoplasma gondii antibodies. A total of $101(16,83 \%)$ of the tested samples were reactive to N. caninum, while $295(49,17 \%)$ of the samples were reactive to T. gondii. $54(9,00 \%)$ of the animals tested showed detectable antibody levels for both coccidia. Cows with serum that reacted positively to both these protozoon parasites were seen in all counties assessed. Statistical differences $(P<0,05)$ between counties were observed when comparing the results of the sera evaluation. It can be concluded from the obtained results that the protozoan parasites $N$. caninum and $T$. gondii are largely widespread in cattle from the assessed counties in Brazil and that the simultaneous occurrence of antibodies for both parasites can be relatively high $(9,00 \%)$ in bovine hosts in the studied geographical region.

Key words: Neospora caninum, Toxoplasma gondii, frequence, cattle.

\section{Introdução}

Em 1984, na Noruega, Bjerkas et al. identificaram um protozoário semelhante ao Toxoplasma gondii em cães com sintomatologia nervosa, porém sem a detecção de anticorpos contra este parasito. Posteriormente, Dubey et al. (1988), observando um quadro similar ao descrito pelos pesquisadores noruegueses, sugeriram um novo gênero e espécie, classificado dentro do filo Apicomplexa, família Sarcocystidae, o Neospora caninum.

Os cães são os hospedeiros definitivos do parasito, sendo taquizoítos, cistos teciduais contendo bradizoítos e oocistos, as formas de desenvolvimento (McALLISTER et al., 1998). Os oocistos eliminados nas fezes do hospedeiro definitivo (cães), permanecem viáveis por longo período e são consumidos pelo hospedeiro intermediário por meio de alimentos contaminados (ANDREOTTI, 2001).
Embora estudos soroepidemiológicos demonstrem que oocistos constituem-se em um dos fatores para a manutenção do parasito no rebanho leiteiro (PARÉ et al., 1998; BARTELS et al., 1999), a transmissão vertical é o modo mais freqüente da infecção pelo $N$. caninum (ANDERSON et al., 1997; BERGERON et al., 2000).

A neosporose vem se destacando como uma importante doença reprodutiva na pecuária leiteira e de corte, acarretando perdas econômicas significativas (DUBEY et al., 1988). Esta enfermidade provoca diminuição na produção de leite, descarte prematuro de animais sororeagentes e aborto entre o terceiro e o nono mês de gestação (JOURNEL e PITEL, 2001). Na Califórnia (EUA), os prejuízos causados pelo $N$. caninum na indústria leiteira foram estimados em torno de 35 milhões de dólares por ano (ANDREOTTI, 2001).

Segundo Dubey e Lindsay (1996), a neosporose tem distribuição mundial, sendo considerada causa de

${ }^{1}$ CPPAR - Centro de Pesquisas em Sanidade Animal, FCAV/Unesp, Campus de Jaboticabal-SP.

${ }^{2}$ Aluno de Pós-Graduação, FCAV/UNESP, Jaboticabal.

${ }^{3}$ Docente da UFU, Uberlândia-MG. 
aborto em bovinos em diversos países como Taiwan (OOl et al.,2000), República da Coréia (BAE et al., 2000), Vietnã (HUONG et al., 1998), Turquia (EREN et al., 1997), Estados Unidos (ANDERSON et al., 1995), Grã-Bretanha (OTTER et al., 1995), e Nova Zelândia (THORNTON et al., 1991). Na Califórnia (EUA), foi diagnosticada em $42 \%$ dos casos de abortos em bovinos (ANDERSON et al., 1995), sendo considerada a principal causa desta patologia (BARR et al., 1990), assim como na Holanda e Nova Zelândia (ANDREOTTI, 2001).

No Brasil, foram detectados anticorpos contra $N$. caninum em soros de bovinos leiteiros e de corte, pertencentes a rebanhos localizados nos Estados de São Paulo (BELO et al.,1999; RESENDE et al., 1999; SARTOR et al., 1999), Mato Grosso do Sul (BRAUTIGAM et al., 1996; ANDREOTIl et al., 1999), Bahia (GONDIM et al., 1999) e Paraná (OGAWA, 2000).

Vários autores relatam a correlação entre a soroprevalência e o aborto (DAVISON et al., 1999; MAINAR-JAIME et al., 1999). Gondim et al. (1999) verificaram que a soroprevalência em vacas com histórico de aborto foi 3,4 vezes superior $(41,17 \%)$, quando comparada com as vacas sem abortamento (12,19\%). Vacas sororreagentes ao $N$. caninum tem duas a três vezes mais chances de abortar do que as com sorologia negativa (WALDNER et al.,1998; WOUDA et al.,1998), sendo o risco de ter um bezerro natimorto 28 vezes maior (JOURNEL e PITEL, 2001).

O diagnóstico de neosporose bovina pode ser realizado através das técnicas que revelam a presença do parasito, como histologia, imunohistoquímica e amplificação dos genes (PCR), ou por técnicas que evidenciam a presença de anticorpos, como reação de imunofluorescência indireta (RIFI), métodos imunoenzimáticos (ELISA) e soroaglutinação (JOURNEL e PITEL, 2001).

Conrad et al. (1993) desenvolveram o primeiro teste sorológico (reação de imunofluorescência indireta-RIFI) para detecção de anticorpos contra $N$. caninum em bovinos. O ponto discriminativo ("cut-off") indicativo de infecção em bovinos ainda não foi totalmente padronizado, porém em revisão sobre o $N$. caninum, foi considerado como específico o ponto discriminativo de 200 (DUBEY e LINDSAY, 1996).

A toxoplasmose, zoonose de caráter cosmopolita, é causada pelo Toxoplasma gondii, coccídio intestinal de felídeos, sendo o gato doméstico o principal hospedeiro definitivo, o qual participa da cadeia epidemiológica da infecção, como disseminador do parasito no meio ambiente. A doença natural em bovinos foi diagnosticada, pela primeira vez, na Alemanha, por Houersdorf e Holtz (1952), citados por Mayer (1965). A infecção nos bovinos ocorre principalmente através da ingestão de oocistos presentes nos alimentos (pastagem, ração, etc.) e solo contaminados (COUTINHO et al., 1982; DUBEY, 1986).
No Brasil, alguns estudos sobre freqüência da infecção toxoplásmica (MARANA et al., 1995; COSTA e COSTA, 1978; COSTA et al., 1978; GARCIA et al., 1999) possibilitam afirmar que esta zoonose está amplamente disseminada entre os bovinos, com percentagens de sororeagentes variando entre $9 \%$ e $48,51 \%$.

$N$. caninum e T. gondii são importantes causas de problemas reprodutivos, isolados ou associados a outros agentes (DUBEY e LINDSAY, 1996). Podem ser diferenciados pela detecção de diferentes antígenos por meio de imunohistoquímica (IHQ) e provas sorológicas, assim como pelas diferenças na espessura da parede cística e número de roptrias do taquizoíto (DUBEY et al., 1988; BARR et al., 1991). Recentemente foi descoberto um marcador genético (IGS-Intergenic Spacer polymorphism) para diferenciação entre as cepas de $T$. gondii e $N$. caninum (FAZAELI et al., 2000). Com relação aos oocistos, são necessários estudos mais profundos para a diferenciação entre os coccídios, pois possuem características estruturais semelhantes (LINDSAY et al., 1999).

Em virtude da ausência de dados sobre a epidemiologia da neosporose e da toxoplasmose bovina nas localidades estudadas, projetou-se o presente trabalho que teve por objetivo principal verificar a freqüência de anticorpos contra $N$. caninum e T. gondii em soros de vacas pertencentes a propriedades rurais dos municípios de Pirangi, Votuporanga, Guaíra e Ituverava, Estado de São Paulo, e dos municípios de Iturama e Gurinhatã, Estado de Minas Gerais.

\section{Material e Métodos \\ 2.1 Colheita de sangue e obtenção dos soros}

Foram colhidas em frigoríficos, no período de agosto a outubro de 2000, 600 amostras de sangue de bovinos pertencentes a rebanhos localizados nos municípios de Pirangi, Votuporanga, Guaíra e Ituverava, Estado de São Paulo e nos municípios de Iturama e Gurinhatã, Estado de Minas Gerais. Foram colhidos apenas sangue de fêmeas, pela grande possibilidade de $N$. caninume T. gondii estarem intimamente ligados a distúrbios reprodutivos, como aborto. Considerando que as vacas amostradas apresentavam variado grau de mestiçagem, não foi possível determinar se pertenciam a rebanhos de corte ou leiteiros.

As amostras foram obtidas por meio de punção venosa, sendo armazenadas em tubos de ensaio sem anticoagulante e encaminhadas para o "Centro de Pesquisas em Sanidade Animal (CPPAR)", pertencente à Faculdade de Ciências Agrárias e Veterinárias Campus de Jaboticabal, Universidade Estadual Paulista (UNESP), onde obtiveram-se os soros, por centrifugação a 5000 rpm por 10 minutos. Cada amostra foi devidamente identificada e acondicionada à temperatura de $-18^{\circ} \mathrm{C}$, até a realização das provas imunológicas. 
2.2 Exames Sorológicos

\subsubsection{Reação de Imunofluorescência Indireta (RIFI) para detecção de anticorpos contra $N$. caninum}

Lâminas marcadas com antígenos de $N$. caninum (cepa JPA-1) foram utilizadas no exame sorológico. A triagem foi realizada na diluição de 1:200 $(5 \mu$ l de soro diluído em $995 \mu$ l de PBS). O conjugado anti-IgG bovino, marcado com isotiocianato de fluoresceína, foi instilado (10 a $20 \mu \mathrm{l}$ ) em todas as cavidades das lâminas. As lâminas, adicionadas de glicerina e lamínula, foram envolvidas em papel alumínio e estocadas em temperatura de $4^{\circ} \mathrm{C}$ até a leitura. Seguindo o mesmo procedimento, todas as amostras positivas foram novamente examinadas em diluições seqüenciais na base dois, até 1:3200. A leitura foi efetuada em microscópio epifluorescente com objetiva de 40 vezes. As reações com título igual ou maior que 200 foram consideradas positivas, evidenciando taquizoítos com fluorescência periférica total mínima de $50 \%$.

\subsubsection{Reação de Imunofluorescência Indireta (RIFI) para detecção de anticorpos contra $T$. gondii}

Para pesquisa de anticorpos anti- $T$. gondii foram utilizadas lâminas contendo taquizoítos da cepa padrão $(\mathrm{RH})$ do parasito, e soros controles com títulos previamente conhecidos. A triagem dos soros foi feita na

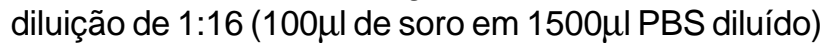
e 1:64 $(100 \mu \mathrm{l}$ de soro diluído 1:16 em 300 $\mu \mathrm{l}$ de PBS diluído). À semelhança do que foi realizado na RIFI para $N$. caninum, as lâminas foram instiladas com 10 a 20 $\mu \mathrm{l}$ do conjugado anti-bovino ( $\mathrm{lgG}$ ) marcado com isotiocianato de fluoresceína, e posteriormente, após adição de glicerina tamponada, cobertas com lamínulas e examinadas em microscópio epifluorescente, com objetiva de 40 vezes. Todos os soros positivos na diluição 1:64 foram novamente diluídos seqüencialmente na base 4 até a obtenção do título final.

\subsection{Análise Estatística}

Para interpretação epidemiológica dos resultados sorológicos obtidos, foi aplicado o Método do Quiquadrado, com nível de significância variando de 0,1 a $5 \%$.

\section{Resultados e Discussão}

Os resultados da sorologia (RIFI-lgG) referentes à freqüência de anticorpos para $N$. caninum e $T$. gondii nos municípios analisados estão presentes na Tabela 1.

Das 600 amostras de soro bovino analisadas pela RIFI (ponto discriminativo 200), 101 (16,83\%) apresentaram anticorpos contra N.caninum. Esses resultados estão próximos dos relatados em bovinos de pecuária leiteira de outras regiões do país, como os descritos por Gondim et al. (1999) no Estado da Bahia, os quais obtiveram $14,09 \%$ de animais sororeagentes a este parasito. Por outro lado, Brautigam et al. (1996) e Andreotii et al. (1999) encontraram $8,00 \%$ e $7,70 \%$ de sororeagentes (ELISA Teste) em bovinos de corte, pertencentes a propriedades do Estado de Mato Grosso do Sul. Possivelmente, o método sorológico utilizado interferiu nos resultados obtidos.

Percentual semelhante foi observado na região de Avaré, Estado de São Paulo, por Sartor et al. (1999), que encontraram freqüência de $16,30 \%$ para o $N$. caninum, enquanto Ogawa (2000), na região norte do Estado do Paraná, detectou $12,00 \%$ de animais sororreagentes ao $N$. caninum nos rebanhos analisados pela RIFI.

Belo et al. (1999) e Resende et al. (1999), na região nordeste do Estado de São Paulo, obtiveram resultados de $22,22 \%$ e $62,90 \%$ de sororeagentes pela RIFI, respectivamente. Os resultados elevados podem ser devido ao ponto discriminativo (100) utilizado pelos autores, o que pode ter superestimado o número de animais positivos. No sul do Vietnã, Huong et al. (1998), por meio da RIFI, detectaram uma menor porcentagem

Tabela 1 - Freqüência de anticorpos contra Neospora caninum e Toxoplasma gondii (RIFI-lgG), em soros de vacas pertencentes aos municípios de Pirangi, Votuporanga, Guaíra e Ituverava, Estado de São Paulo e aos municípios de Iturama e Gurinhatã, Estado de Minas Gerais. CPPAR/UNESP, Jaboticabal, SP.

\begin{tabular}{|c|c|c|c|c|c|}
\hline \multirow{3}{*}{ Municípios } & \multicolumn{5}{|c|}{ Soros examinados } \\
\hline & \multicolumn{2}{|c|}{ Neospora caninum } & \multicolumn{2}{|c|}{ Toxoplasma gondii } & \multirow{2}{*}{ Total } \\
\hline & Sororreagentes (\%) & Não reagentes (\%) & Sororreagentes (\%) & Não reagentes (\%) & \\
\hline Pirangi & $24(16,67)$ & $120(83,33)$ & $78(54,17)$ & $66(45,83)$ & $144(24,00)$ \\
\hline Votuporanga & $41(25,15)$ & $122(74,85)$ & $102(62,58)$ & $61(37,42)$ & $163(27,17)$ \\
\hline Guaíra & $20(13,70)$ & $126(86,30)$ & $70(47,94)$ & $76(52,06)$ & $146(24,33)$ \\
\hline Ituverava & $10(18,87)$ & $43(81,13)$ & $30(56,60)$ & $23(43,40)$ & $53(8,83)$ \\
\hline Iturama & $4(5,41)$ & $70(94,59)$ & $12(16,22)$ & $62(83,78)$ & $74(12,33)$ \\
\hline Gurinhatã & $2(10,00)$ & $18(90,00)$ & $3(15,00)$ & $17(85,0)$ & $20(3,33)$ \\
\hline Total & $101(16,83)$ & $499(83,17)$ & $295(49,17)$ & $305(50,83)$ & $600(100)$ \\
\hline
\end{tabular}


de bovinos sororeagentes (5,50\%). Essa diferença poderia ser justificada pelos contrastes de ecossistemas entre as duas regiões, ou devido ao ponto discriminativo (640) adotado pelos autores, o que pode ter resultado em animais falso negativos.

Já a soroprevalência encontrada por Bae et al. (2000), na Republica da Coréia, foi de $23 \%$ para $N$. caninum utilizando o ensaio imunoenzimático (ELISA). Esta diferença pode ser explicada devido ao método diferente de análise sorológica que os autores utilizaram.

A pesquisa de anticorpos contra $T$. gondii resultou em $295(49,17 \%)$ animais sororeagentes, valores próximos aos relatados por Marana et al. (1995), que detectaram anticorpos contra T. gondii, através da RIFI (ponto discriminativo 64 ), em $48,51 \%$ dos soros examinados de bovinos, procedentes da região norte do Estado do Paraná.

Nos municípios de Ankara e Aydin, Turquia, Eren et al. (1997) detectaram, pelo Teste Sabin-Feldman, soroprevalência de $60,2 \%$ e $66 \%$ para $T$. gondii respectivamente para os dois municípios. Novamente, o diferente método utilizado na investigação sorológica pode explicar as diferenças no resultado.

$\mathrm{Na}$ Figura 1, pode-se observar a distribuição percentual dos resultados sorológicos ( $N$. caninum e $T$. gondii) obtidos nas 600 vacas oriundas dos seis municípios analisados. Fato notório foi que 54 animais $(9,00 \%)$ apresentaram títulos de anticorpos para ambos os coccídios. Em Taiwan, este fato ocorreu em 12,56\% de 613 soros examinados pela RIFI (OOI et al., 2000).

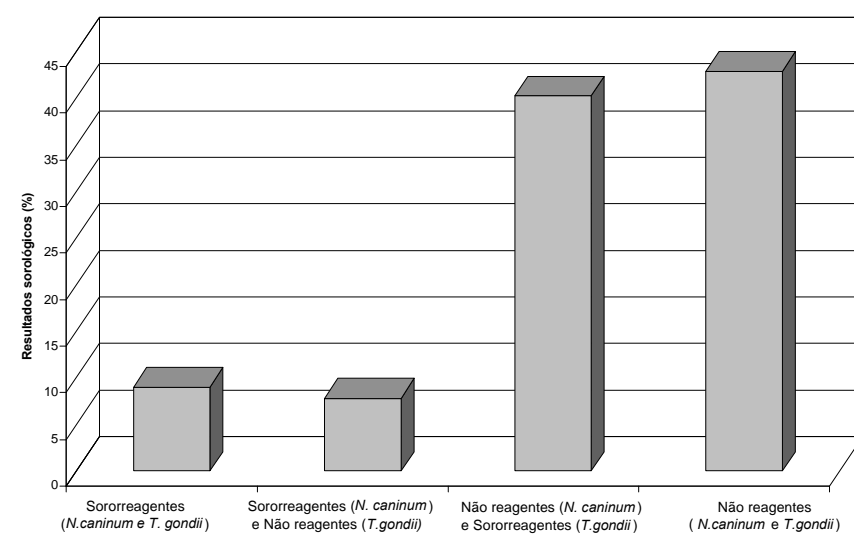

Figura 1 - Distribuição percentual dos resultados sorológicos (Neospora caninum e Toxoplasma gondii) obtidos em 600 vacas oriundas de seis municípios dos estados de São Paulo e Minas Gerais. CPPAR/UNESP, Jaboticabal, SP.

A ocorrência simultânea de anticorpos contra ambos os coccídios na RIFI também foi relatada por Gondim et al. (1999). Os autores observaram que, das 63 vacas sororeagentes ao $N$. caninum, três $(4,76 \%)$ foram sororreagentes ao $T$. gondii. Os títulos desses animais foram de 64 para $T$. gondii e de 200, 400 e 800 para $N$. caninum, respectivamente.

No presente estudo, entre todas as localidades avaliadas, a região de Votuporanga, Estado de São Paulo, apresentou a maior freqüência de animais sororreagentes, tanto para N.caninum como T.gondii, com índices de $25,15 \%$ e $62,58 \%$ de casos, respectivamente.

Em todos os municípios estudados, foi constatada a presença de animais sororeagentes ao $N$. caninum e ao T. gondii. Diferenças significativas (método de $\mathrm{X}^{2}$ ), foram observadas para $N$. caninum entre os municípios de Iturama e Pirangi $(P<0,05)$, Iturama e Ituverava $(P<0,02)$, Votuporanga e Guaíra $(P<0.02)$ e entre as localidades de Iturama e Votuporanga $(P<0,001)$. Para T. gondii, diferenças significativas $(P<0,01)$ foram encontradas entre os municípios de Gurinhatã e Pirangi, Gurinhatã e Guaíra, Gurinhatã e Ituverava e entre Votuporanga e Guaíra. Também foram detectados diferenças significativas $(P<0,001)$ para $T$. gondii entre os municípios de Iturama e Pirangi, Iturama e Votuporanga, Iturama e Guaíra, Iturama e Ituverava e entre Gurinhatã e Votuporanga. Tais diferenças devem-se, possivelmente, ao fato de os municípios compartilharem regiões de ecossistemas e práticas de manejo diferentes, com fatores que favorecem ou não o estabelecimento das infecções por N. caninum e por T. gondii.

Em contraposição, Mainar-Jaime et al. (1999), examinando bovinos procedentes de 43 propriedades leiteiras, pertencentes a três municípios da região da Astúria - Espanha, não encontraram diferença estatística entre os percentuais de sororeagentes a N. caninum, quanto à procedência dos animais.

A escassez de literatura brasileira sobre $N$. caninum e T. gondii, particularmente em bovinos de corte dos Estados de São Paulo e de Minas Gerais, impossibilita uma discussão mais profunda dos resultados obtidos com esta investigação sorológica. Entretanto, tais resultados evidenciam que tais protozooses necessitam de estudos mais amplos para que sejam avaliadas, com mais fidedignidade, a distribuição geográfica e a importância econômica das mesmas, nas diferentes regiões do Brasil.

\section{Referências bibliográficas}

ANDERSON, M.L.; PALMER, C.W.; THURMOND, M.C.; PICANSO, J.P.; BLANCHARD, P.C.; BRETMEYER, R.E.; LAYTON, A.W.; McALLISTER, M.; DAFT, B.; KINDE, H.; READ, D.H.; DUBEY, J.P.; CONRAD, P.A.; BARR, B.C. Evaluation of abortions in cattle attributable to neosporosis in selected dairy herds in California. J Am Vet Med Assoc, Schaumburg, v. 207, n. 09, p. 1206-1210, 1995.

ANDERSON, M.L.; REYNOLDS, J.P.; ROWE, J.D.; SVERLOW, K.W.; PACKAM, A.E.; BARR, B.C.; CONRAD, P.A. Evidence of vertical transmission of Neospora sp infection in dairy cattle. J Am Vet Med Assoc, Schaumburg, v.210, n.08, p.1169-1172, 1997.

ANDREOTII, R. Neosporose: um possível problema reprodutivo para o rebanho bovino. $H$ Vet, Porto Alegre, n.122, p.65-67, 2001.

ANDREOTTI, R.; PINCKNEY, R.; GOMES, A. Diagnóstico sorológico de Neospora caninum em rebanho bovino de corte do Mato Grosso do Sul. In: SEMINÁRIO BRASILEIRO DE PARASITOLOGIA VETERINÁRIA, 11., 1999, Salvador- 
BA. Anais... Salvador: Colégio Brasileiro de Parasitologia Veterinária, 1999, p.226.

BAE, J.S.; KIM, D.Y.; HWANG, W.S.; KIM, J.H.; LEE, N.S.; NAM, H.W. Detection of IgG antibody against Neospora caninum in cattle in Korea. Korean J Parasitol, v.38, p.245249, 2000.

BARR, B.C.; CONRAD, P.A.; DUBEY, J.P.; ANDERSON, M.L. Neospora-like encephalomyelitis in a calf:pathology, ultrastructure, and immunoreactivity. J Vet Diagn Invest, Columbia, v.03, p. 39-46, 1991.

BARTELS, C.J.M.; WOUDA, W.; SCHUKKEN, Y.H. Risk factors for Neospora caninum-associated abortion storms in dairy herds in The Netherlands (1995-1997). Theriogenology, Stoneham, v.52, p.247-257, 1999.

BELO, M.A.A.; REZENDE, P.C.B.; SOUZA, L.M.; COSTA, A.J. Presença de anticorpos anti-Neospora caninum em bovinos com histórico de abortos não diagnosticados etiologicamente. In: SEMINÁRIO BRASILEIRO DE PARASITOLOGIA VETERINÁRIA, 11., 1999. Salvador-BA. Anais... Salvador: Colégio Brasileiro de Parasitologia Veterinária, 1999, p. 228.

BERJERON, N.; FECTEAU, G.; PARE, J.; MARTINEAU, R.; VILLENEUVE, A. Vertical and horizontal transmission of Neospora caninum in dairy herds in Quebec. Can Vet J, Ottawa, v.41, n.6, p.464-469, 2000.

BJERKAS, I.; MOHN, S.F.; PRESTHUS, J. Unidentified cystforming sporozoon causing encephalomyelitis and myositis in dogs. Z Parasitenkd, Jena, v.70, p.271-274, 1984.

BRAUTIGAM, F.E.; HIETALA, S.K.; GLASS, R. Resultados de levantamento sorológico para a espécie Neospora em bovinos de corte e leite. In: CONGRESSO PANAMERICANO DE CIÊNCIAS VETERINÁRIAS, 15., 1996, Campo Grande, MS. Anais... Campo Grande: Associação Panamericana de Ciências Veterinárias, 1996, p.284.

CONRAD, P.A. SVERLOW, K.W.; ANDERSON, M.A.; ROWE, J.; BONDURANT, R.; TUTER, G.; BREITMEYER, R.; PALMER, C.; THURMOND, M.; ARDANS, A.; DUBEY, J.P.; DUHAMEL, G.; BARR, B.C. Detection of serum antibody responses in cattle with natural or experimental Neospora infections. $J$ Vet Diagn Invest, Columbia, v.5, p.572-578, 1993.

COSTA, A.J. e COSTA, E.P. Freqüência de bovinos reagentes à reação de Imunofluorescência Indireta para Toxoplasma gondii em Poços de Caldas, MG,Brasil. Arq Esc Vet, Belo Horizonte, v.30, n.1, p.47-51, 1978.

COSTA, A.J.; KASAI, N.; PAULILLO, A.C.; SILVA, M.B.; GALESCO, H. Anticorpos anti-Toxoplasma em soros de bovinos do município de Jaboticabal, S.P., Brasil. Arq. Inst. Biol., São Paulo, v.45, n.4, p.299-302, 1978.

COUTINHO, S.G.; LOBO, R.; DUTRA, G. Isolation of Toxoplasma from the soil during an outbreak of toxoplasmosis in a rural area in Brazil. J Parasitol, Lancaster, v. 68, n. 05, p. 866-868, 1982.

DAVISON, H.C.; OTTER, A.; TREES, A.J. Significance of Neospora caninum in British dairy cattle determined by estimation of seroprevalence in normally calving cattle and aborting cattle. Int J Parasitol, Elsford, v. 29, n. 08, p. 11891194, 1999.

DUBEY, J.P. Toxoplasmosis. J Am Vet Med Assoc, Schaumburg, v. 189, n.2, p. 166-170, 1986.
DUBEY, J.P.; LINDSAY, D.S. A review of Neospora caninum and neosporosis. Vet Parasitol, Amsterdam, v.67, p.1-59, 1996.

DUBEY, J.P.; CARPENTER, J.L.; SPEER, C.A.; TOPPER, M.J.; UGGLA, A. Newly recognized fatal protozoan disease of dogs. J Am Vet Med Assoc, v.192, p.1269-1285, 1988.

EREN, H.;BABUR, C.; ERDAL, N.; SERT, H. The prevalence of Toxoplasma gondii in cattle in Ankara and Aydin by the Sabin-Feldman test. Turk Hij Deneysel Biyol Derg, v.54, p.31-34, 1997.

FAZAELI, A.; CARTER, P.E.; PENNINGTON, T.H. Intergenic spacer (IGS) polymorphism: a new genetic marker for differenciation of Toxoplasma gondii strains and Neospora caninum. J Parasitol, Lancaster, v.86, n.4, p.716-723, 2000.

GARCIA, J.L.; NAVARRO, I.T.; OGAWA, L.; OLIVEIRA, R.C. Soroprevalência do Toxoplasma gondii em suínos, bovinos, ovinos e eqüinos, e sua correlação com humanos, felinos e caninos, oriundos de propriedades rurais do norte do Paraná-Brasil. Semina: Ci Agro, Londrina, v.29, n. 1, p.9197, 1999.

GONDIM, L.F.P.; SARTOR, I.F.; HASEGAWA, M.; YAMANE, I. Seroprevalence of Neospora caninum in dairy cattle in Bahia, Brazil. Vet Parasitol, Amsterdam, v. 86, p. 71-75, 1999.

HUONG, L.T.T.; LJUNGSTROM, B.L.; UGGLA, A.; BJORKMAN, C. Prevalence of antibodies to Neospora caninum and Toxoplasma gondii in cattle and water buffaloes in southern Vietnam. Vet Parasitol, Amsterdam, v.75, p.53-57, 1998.

JOURNEL, C.; PITEL, P.H. Diagnóstico da neosporose em bovinos. $H$ Vet, Porto Alegre, n.122, p.70-72, 2001.

LINDSAY, D.S.; UPTON, S.J.; DUBEY, J.P. A structural study of the Neospora caninum oocyst. Int J Parasitol, Elmsford, v.29, n.10, p.1521-1523, 1999.

MAINAR-JAIME, R.C.; THURMOND, M.C.; BERZALHERRANZ, B.; HIETALA, S.K. Seroprevalence of Neospora caninum and abortion in dairy cows in northern Spain. Vet Rec, London, v. 145, p. 72-75, 1999.

MARANA, E.R.M.; NAVARRO, I.T.; VIDOTTO, O.; FREIRE, R.L; VENTURINI, A.C.H. Ocorrência de anticorpos antiToxoplasma gondii em rebanhos de bovinos de leite no norte do Paraná-Brasil. Semina, Londrina, v. 16, n.1, p. 4042, 1995.

MAYER, H.F. Investigaciones sobre toxoplasmosis. Bol Of Sant Panm, Washington, v.58, n.6, p.485-497, 1965.

McALLISTER, M.M.; DUBEY, J.P.; LINDSAY, D.S.; JOLLEY, W.R.; WILLIS, R.A.; McGUIRE, A.M. Dogs are definitive hosts of Neospora caninum. Int J Parasitol, Elmsford, v.28, p.1473-1478, 1998.

OGAWA, L. Estudo soroepidemiológico do Neospora caninum e Toxoplasma gondii em bovinos de pecuária leiteira da região norte do Estado do Paraná. 2000. Tese (Mestrado em Sanidade Animal) - Departamento de Medicina Veterinária Preventiva, Universidade Estadual de Londrina, Londrina, 2000.

OOI, H.K.; HUANG, C.C.; YANG, C.H.; LEE, S.H. Serological survey and first finding of Neospora caninum in Taiwan, and the detection of its antibodies in various body fluids of cattle. Vet Parasitol, Amsterdam, v.90, p.47-55, 2000. 
OTTER, A.; JEFFREY, M.; GRIFFITHS, I.B.; DUBEY, J.P. A survey of the incidence of Neospora caninum infection in aborted and stillborn bovine fetuses in England and Wales. Vet Rec, London, v. 136, p. 602-606, 1995.

PARÉ, J.; FECTEAU, G.; FORTIN, M.; MARSOLAIS, G. Seroepidemiologic study of Neospora caninum in dairy herds. J Am Vet Med Assoc, Schaumburg, v.213, n.11, p.1595-1598, 1998.

RESENDE, P.C.B.; BELO, M.A.A.; MARCHIORI FILHO, M.; COSTA, A.J.; SILVEIRA, D.M. Anticorpos anti-Neospora caninum em bovinos leiteiros da região nordeste do Estado de São Paulo, Brasil. In: SEMINÁRIO BRASILEIRO DE PARASITOLOGIA VETERINÁRIA, 11., 1999. Salvador-BA. Anais... Salvador: Colégio Brasileiro de Parasitologia Veterinária, 1999, p.229.

SARTOR, I.F.; HASEGAWA, M.Y.; GONDIM, L.F.P.; PIAGENTINI, M.; VIEIRA, A.; MEGID, J.; CANAVESSI, A.M. Prevalência de anticorpos contra Neospora caninum em rebanhos leiteiros do município de Avaré, SP. Resultados preliminares. In: SEMINÁRIO BRASILEIRO DE PARASITOLOGIA VETERINÁRIA, 11., 1999. Salvador-BA. Anais... Salvador: Colégio Brasileiro de Parasitologia Veterinária, 1999, p. 225.

THORNTON, R.N.; THOMPSON, E.J.; DUBEY, J.P. Neospora abortion in New Zealand cattle. $N Z$ Vet $J$, Wellington, v.39, p.129-133, 1991.

WALDNER, C.L.; JANZEN, E.D.; RIBBLE, C.S. Determination of the association between Neospora caninum infection and reproductive performance in beef herds. J Am Vet Med Assoc, London, v.216, n.5, p.685-690, 1998.

WOUDA, W.; MOEN, A.R.; SCHUKKEN, Y.H. Abortion risk in progeny of cows after a Neospora caninum epidemic. Theriogenoly, Stoneham, v.49, p.1311-1316, 1998. 